\title{
Technical note: Validation of a chemical pregnancy test in dairy cows that uses whole blood, shortened incubation times, and visual readout
}

\author{
L. M. Mayo, ${ }^{*}$ S. G. Moore, ${ }^{*}$ S. E. Poock, $†$ W. J. Silvia, $\neq^{1}$ and M. C. Lucy ${ }^{2}$ \\ *Division of Animal Sciences, and \\ †Veterinary Medicine Extension, University of Missouri, Columbia 65211 \\ łDepartment of Animal and Food Sciences, University of Kentucky, Lexington 40546
}

\begin{abstract}
Chemical pregnancy testing is an alternative to traditional methods of pregnancy diagnosis (either manual palpation or ultrasound) in postpartum dairy cows and heifers. The objective was to validate a chemical pregnancy test that confers the advantages of using whole blood, rapid incubation times, and visual readout. Blood and milk samples were collected from Holstein dairy cows $[\mathrm{n}=320 ; 162 \pm 62$ (mean $\pm \mathrm{SD}) \mathrm{d}$ in milk] on a confinement farm in northeast Missouri at $28 \mathrm{~d}$ after artificial insemination (AI). The samples were assayed for pregnancy-associated glycoproteins (PAG) by using a rapid visual test as well as traditional plasma- and milk-based tests. Transrectal ultrasonography diagnosis for pregnancy at 35 to $38 \mathrm{~d}$ after AI was the reference (gold) standard for all PAG tests. One hundred fifty-nine cows were diagnosed as pregnant by the reference standard (pregnancies per $\mathrm{AI}=49.7 \%$ ). The tests were ELISA and either optical density (OD; measured with a microtiter plate reader; plasma, milk, and rapid visual tests) or visual readout (rapid visual test) were used to diagnose pregnancy. When OD was used, the percentage of pregnant cows classified correctly (sensitivity) for the plasma, milk, and rapid visual tests were $97 \pm 1,96 \pm 2$, and $95 \pm$ $1 \%( \pm \mathrm{SE})$, respectively. The sensitivity of the rapid visual test when assessed visually was $98 \pm 1 \%$. The specificity (proportion of nonpregnant cows classified correctly) for the plasma, milk, and rapid visual was $94 \pm 2 \%, 94 \pm 2 \%$, and $93 \pm 2 \%$ when an OD was used. When read visually, the specificity of the rapid visual test was lesser $(85 \pm 3 \%)$ because some cows with faint visual signals yielded false positive diagnosis. The overall accuracy (proportion of pregnant and nonpregnant cows diagnosed correctly) was similar for all tests (plasma, milk, rapid visual OD, and rapid visual;
\end{abstract}

Received March 27, 2016

Accepted May 20, 2016.

${ }^{1}$ Deceased.

${ }^{2}$ Corresponding author: lucym@missouri.edu
$96 \pm 1,95 \pm 1,94 \pm 1$, and $92 \pm 2 \%$, respectively). In a second experiment, lactating Holstein cows $(\mathrm{n}=291)$ from 4 commercial confinement dairy farms in western Kentucky were tested 25 to $95 \mathrm{~d}$ after AI using the rapid visual test. The OD of the rapid visual test followed the known profile for PAG in circulation during the first trimester of pregnancy. The conclusion is that the rapid visual test has equal sensitivity and accuracy as existing PAG tests. A slightly lower specificity was found when the rapid visual test was read visually.

Key words: pregnancy diagnosis, pregnancy-associated glycoprotein, ELISA

\section{Technical Note}

Pregnancy diagnosis within 4 to 6 wk after AI in postpartum dairy cows is critical for identifying nonpregnant cows eligible for rebreeding so that time from calving to conception (days open) is less (Silva et al., 2009; Giordano et al., 2013). Traditional methods of pregnancy diagnosis such as ultrasonography or manual palpation are typically performed 32 or more days after AI (Fricke, 2002). Earlier tests are based on pregnancyassociated glycoproteins (PAG) in the circulation that are detected as early as $25 \mathrm{~d}$ after AI in cattle (Green et al., 2005, 2009; Wallace et al., 2015). The PAG can be detected in either plasma, serum, or milk (Silva et al., 2007; LeBlanc, 2013; Lawson et al., 2014). The accuracies of commercial PAG tests for plasma, serum, or milk range from 89 to $96 \%$ (Silva et al., 2007; Karen et al., 2015; Ricci et al., 2015). The accuracy of PAG tests makes them suitable alternatives to traditional methods of pregnancy diagnosis (palpation or ultrasound). There are limitations, however, to their use. Plasma or serum-based tests require the collection of a blood sample and subsequent centrifugation. The centrifugation step requires equipment that is typically not available on farm. Milk testing does not require centrifugation, but the initial assay step requires a thermally controlled platform shaker for the ELISA plate. Shaking is not required for assays performed with plasma or serum, but an incubator is needed. Regardless of whether plas- 
ma, serum, or milk is used, a microtiter plate reader is required to measure the optical density (OD) for individual wells in the ELISA plate. Given the need for specialized equipment, PAG testing is most likely done in a veterinary clinic or other centrally located laboratory. A final impediment to the on-farm test is the time from sample collection to pregnancy test result. Traditional tests have a series of incubations with antibody and reagent solutions that can require from 2 to $3 \mathrm{~h}$ or as long as overnight to complete the test. In many herds, treatments are administered to nonpregnant cows after pregnancy diagnosis, usually before they are released from animal restraint (headlocks, squeeze chute, or palpation rail). The length of time from sampling to test completion is too long if cows are to remain restrained or kept in separate pens. A lesser time from sampling to test result could improve on-farm utility of a PAG test. We tested a rapid visual PAG test (Rapid Visual Pregnancy Test; Idexx, Westbrook, ME) that addresses some of the limitations listed above. Specifically, whole blood (EDTA) can be used in addition to plasma (EDTA) or serum, total test time is reduced to approximately $30 \mathrm{~min}$, and the plate can be read visually. The objective of this experiment was to validate the rapid visual test performed $28 \mathrm{~d}$ after AI by using transrectal ultrasound on d 35 to 38 as the reference standard. We also compared the results obtained from the rapid visual test with those obtained using traditional PAG tests based on plasma or milk. Finally, the rapid visual test was used to assay a series of samples collected during the first trimester of pregnancy (d 25 to 95).

The validation experiment was performed at a confinement dairy farm in northeast Missouri by using 2 cohorts of lactating Holstein cows $(n=320)$ in January 2016. The cows were $162 \pm 62$ (mean \pm SD) DIM on the day of blood and milk sample collection. Both primiparous $(\mathrm{n}=95)$ and multiparous $(\mathrm{n}=225)$ cows were used (mean $\pm \mathrm{SD}=2.3 \pm 1.2$ calvings). Cows were housed in a standard free-stall, milked 3 times daily, and fed a TMR. Cows were treated with a Presynch Ovsynch_56 protocol $\left[\mathrm{PGF}_{2 \alpha}, 14 \mathrm{~d}, \mathrm{PGF}_{2 \alpha}, 14 \mathrm{~d}\right.$, GnRH, 7 d, $\mathrm{PGF}_{2 \alpha}, 56 \mathrm{~h}, \mathrm{GnRH}, 16 \mathrm{~h}$, timed AI $\left(\mathrm{PGF}_{2 \alpha}\right.$ $=$ Lutalyse, $5 \mathrm{~mL}$ i.m., $25 \mathrm{mg}$, Zoetis Animal Health, Florham Park, NJ; GnRH = Fertagyl, 2 mL i.m., 100 $\mu \mathrm{g}$, Intervet, Milan, Italy)] so that first timed AI was 70 to $76 \mathrm{~d}$ postpartum. Cows submitted to a timed AI (n $=114)$ or resynchronization timed AI $(\mathrm{n}=206)$ were enrolled in the study. The resynchronization protocol began with a GnRH treatment $32 \mathrm{~d}$ after timed AI and concluded with a resynchronized timed AI on d 42 (GnRH, $6 \mathrm{~d}$, ultrasound pregnancy diagnosis, $1 \mathrm{~d}$, and then for nonpregnant cows, $\mathrm{PGF}_{2 \alpha}, 56 \mathrm{~h}, \mathrm{GnRH}, 16 \mathrm{~h}$, timed AI). The number of inseminations at the time of pregnancy diagnosis averaged $2.3 \pm 1.4$ (mean $\pm \mathrm{SD}$ ).

Blood and milk samples were collected $28 \mathrm{~d}$ after timed AI. Cows eligible for pregnancy diagnosis from the herd were identified by radio frequency emitting ear tags upon exit from the parlor and directed to a standard palpation rail that was used to restrain cows during sampling. Blood and milk samples were collected while cows stood in the palpation rail. Blood was collected by coccygeal venipuncture into a Monoject tube containing $100 \mu \mathrm{L}$ of a $15 \%$ solution of EDTA $\left(\mathrm{K}_{3}\right.$; Covidien, Minneapolis, MN). Milk was collected into a 20-mL disposable polyethylene scintillation vial (Fisherbrand, Pittsburgh, PA). Blood and milk sample tubes were placed on crushed ice immediately after collection, transported back to the laboratory within $8 \mathrm{~h}$ of sampling, and stored overnight at $4^{\circ} \mathrm{C}$. The following morning, blood tubes were inverted to mix and approximately $2 \mathrm{~mL}$ of whole blood was transferred to a $12 \times 75 \mathrm{~mm}$ borosilicate glass tube for subsequent use in the rapid visual test. The remaining blood was centrifuged at $1,500 \times g$ for $15 \mathrm{~min}$ at $4^{\circ} \mathrm{C}$. Plasma for use in the conventional test was aspirated into a $12 \times$ $75 \mathrm{~mm}$ polypropylene tube. Milk was mixed thoroughly by inversion before use.

All assays were performed according to the manufacturer's instructions. The purpose of this study was to validate the performance of the rapid visual test (Idexx Rapid Visual Pregnancy Test) relative to transrectal ultrasonography as the reference (gold) standard for pregnancy diagnosis. A conventional test that can use either plasma or serum (Idexx Bovine Pregnancy Test) and a milk-based test (Idexx Milk Pregnancy Test) were also compared with the reference standard as well as to the rapid visual test.

The rapid visual test is a sandwich-style ELISA. It has a similar format to conventional (plasma or serum) and milk tests but some steps are combined and incubation times are shorter. Although performance of the test with whole blood (EDTA) is presented, plasma (EDTA) or serum can also be tested. The manufacturer provides 96-well assay plates comprised of twelve 8-well assay strips. For the rapid visual test, $100 \mu \mathrm{L}$ of whole blood and 3 drops (approximately $100 \mu \mathrm{L}$ ) of reagent 1 detector solution were added to individual wells of the PAG antibody-coated ELISA plate. The plate was covered, tapped gently to mix, and incubated for $7 \mathrm{~min}$ at room temperature $\left(23\right.$ to $\left.26^{\circ} \mathrm{C}\right)$. After $7 \mathrm{~min}$, the solution in the wells was removed by inversion and then the wells were washed thrice with distilled water. For washing, individual wells were gently filled until overflowing by using a 500-mL wash bottle (no. 414004-227; VWR, Radnor, PA) and a flow rate of approximately 
$0.7 \mathrm{~mL} / \mathrm{s}$. Three drops of conjugate solution containing horseradish peroxidase was then added to the wells and a second $7 \mathrm{~min}$ incubation followed by washing was completed. Three drops of tetramethylbenzidine substrate solution was then added and the reaction was stopped after 10 min by adding 3 drops of a stop solution. Each individual assay consisted of 28 unknown samples and negative and positive control samples at the beginning and end of each assay (32 wells total; 4 ELISA plate assay strips). Test results were interpreted according to the manufacturer's recommendations. Absence of color (clear solution) was interpreted as nonpregnant. Cows were classified pregnant if the sample was any shade darker visually than the negative controls. Cows were classified not pregnant if the sample was not darker visually than the negative controls. After the wells were interpreted visually, the OD (absorbance) was read at $650 \mathrm{~nm}$ using a microtiter plate reader (BioTek Synergy HT, Winooski, VT).

The procedures for the conventional (plasma) and milk tests were similar to those described for the rapid visual test but there were methodological differences with respect to incubation conditions and times. Per manufacturer instructions for conventional and milk assay plates, OD was measured at $450 \mathrm{~nm}$ with a reference wavelength of $650 \mathrm{~nm}$. Total incubation times (not including pipetting, washing, or microtiter plate reading) were 21,135 , and $200 \mathrm{~min}$ for the rapid visual, conventional (plasma), and milk tests.

Receiver operator characteristic (ROC) curves were generated from OD using the LOGISTIC procedure in SAS 9.3 (SAS Institute Inc., Cary, NC). The event was the result of the reference standard. The reference standard was defined as the result of pregnancy diagnosis at 35 to $38 \mathrm{~d}$ after AI (approximately 7 to $10 \mathrm{~d}$ after the chemical testing) as performed by a single veterinarian using transrectal ultrasonography (equipment used was an Easi-Scan, BCF Technology, Rochester, MN). Insemination number and parity were included as fixed effects in the model. Cutpoints for pregnancy diagnosis were selected that had the minimal distance from the ROC curve to the "perfect" point at the upper left corner where sensitivity $=1$ and $1-$ specificity $=0$. The GLM procedure in SAS 9.3 was used to test for the effects of parity, insemination number, and days open at the time of sampling on the OD of individual samples.

The sensitivity [(number of cows correctly diagnosed positive with a blood pregnancy test/number of cows with a positive ultrasonographic pregnancy test) $\times$ 100], specificity [(number of cows correctly diagnosed negative with a blood pregnancy test/number of cows with negative ultrasonographic pregnancy test $) \times 100$ ], positive predictive value $[\mathbf{P P V}$; (number of cows correctly diagnosed pregnant with a test/number of cows correctly diagnosed pregnant with a test + the number of cows incorrectly diagnosed pregnant with a test) $\times$ 100], negative predictive value [NPV; (number of cows correctly diagnosed not pregnant with a test/number of cows correctly diagnosed not pregnant with a test + the number of cows incorrectly diagnosed not pregnant with a test) $\times 100]$, and accuracy [ACY; (number of correct blood pregnancy tests/total number of blood pregnancy tests $) \times 100$ ] were calculated for each assay. Differences between assays for sensitivity, specificity, PPV, NPV, and ACY were tested for significance using Fisher's exact test. The data are reported as the proportion $\pm \mathrm{SE}$ where $\mathrm{SE}=$ square $\operatorname{root}(p q / \mathrm{n})$ (Snedecor and Cochran, 1989). The FREQUENCY procedure of SAS 9.3 was used to calculate the Cohen's kappa statistic, which measures the agreement between all methods of pregnancy diagnosis (chemical tests and transrectal ultrasonography).

At the time of diagnosis by ultrasound, 159/320 (49.7\%) cows were pregnant. The area under the ROC curve for the conventional (plasma) test was 0.9754 with a $95 \%$ confidence interval of 0.9592 to 0.9917 (Figure 1A; $P<0.001$ ). A cutpoint of 1.72 for OD at $450 \mathrm{~nm}$ had a sensitivity of $97 \pm 1 \%$ and a specificity of $94 \pm 2 \%$. The area under the curve for the milk-based test for pregnancy was 0.9658 with a $95 \%$ confidence interval of 0.9430 to $0.9887(P<0.001$; Figure 1B). A cutpoint of 0.86 for OD at $450 \mathrm{~nm}$ had a sensitivity of $96 \pm 2 \%$ and a specificity of $94 \pm 2 \%$. The area under the curve for the rapid visual test was 0.9710 with a $95 \%$ confidence interval of 0.9527 to 0.9892 (Figure 1C; $P<0.001)$. A cutpoint of 0.304 for OD at $650 \mathrm{~nm}$ had a sensitivity of $95 \pm 2 \%$ with a specificity of $93 \pm$ $2 \%$. The ROC curves that were generated based on OD for plasma, milk, and rapid visual were similar with respect to area under the curve (ranging from 0.9658 to 0.9754 ) and also sensitivity (ranging from 95 to $97 \%$ ) and specificity (ranging from 93 to $94 \%$ ). The area under the curve for the conventional plasma and milk test using the sample OD minus negative control OD was identical to that using the sample OD alone. We chose not to subtract the negative control OD, therefore, as previous studies have done (LeBlanc, 2013; Ricci et al., 2015) because a reference wavelength was not used for the rapid visual test interpretation. The conclusion was that a useful cutpoint could be found for all tests when the test result was an OD as measured by a microtiter plate reader. Assuming 8.9\% pregnancy loss, Giordano et al. (2013) concluded that the sensitivity and specificity of the chemical tests at d 31 needed to be 96.4 and $95.1 \%$ (respectively) for an equal return on investment with respect to rectal palpation at $39 \mathrm{~d}$ after AI. The sensitivity and specificity of plasma, milk, and rapid visual tests when the results were measured with a 

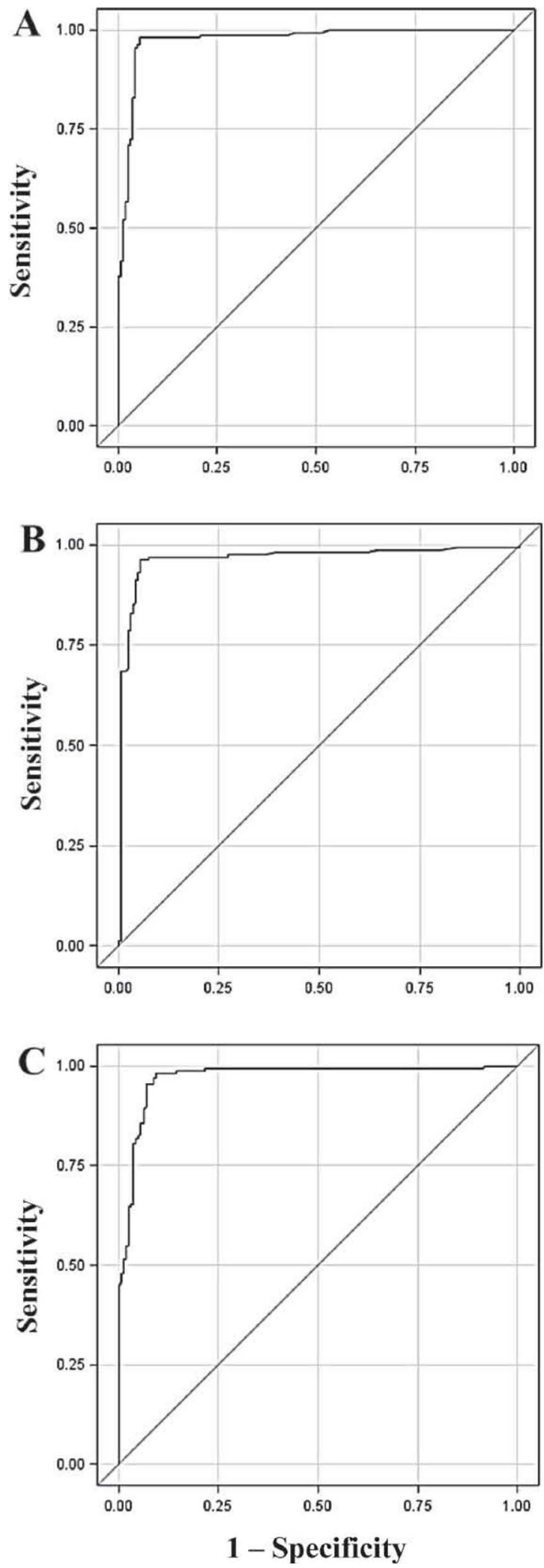

Figure 1. Receiver operator characteristic (ROC) curves for 3 bovine chemical pregnancy tests. (A) Conventional plasma test (area under the curve $=0.9754)$; $(\mathrm{B})$ milk test (area under the curve $=0.9658$ ); and $(\mathrm{C})$ rapid visual test (area under the curve $=0.9710$ ). microtiter plate reader (OD) were almost identical to the break-even numbers proposed by Giordano et al. (2013).

When interpreted visually, the sensitivity of the rapid visual test was $98 \pm 1 \%$ (Table 1 ). The sensitivity for the test was not different $(P>0.10)$ for the rapid visual test when a cutpoint based on OD was used for diagnosis $(95 \pm 2 \%)$ and was not different $(P$ $>0.10)$ from plasma $(97 \pm 1 \%)$ or the milk $(96 \pm 2 \%)$ tests. The specificity of the rapid visual test interpreted visually was $85 \pm 3 \%$ and was less $(P<0.05)$ than the specificity of the rapid visual test interpreted using OD or the specificity of the other tests. The PPV for the rapid visual, plasma, and milk tests when OD was used for interpretation did not differ $(P>0.10$; Table 1$)$. The PPV for the rapid visual test interpreted visually $(87 \pm 3 \%)$ was less $(P<0.05)$ than other tests. The NPV and ACY for the rapid visual test interpreted visually was $98 \pm 1$ and $92 \pm 2 \%$ (respectively) and did not differ from the NPV and ACY of the rapid visual, milk, or plasma tests when OD was used for interpretation.

Fifteen cows had a false negative test result for any test, and 26 cows had a false positive test result for any test (Figure 2). Two of the $15(13 \%)$ cows had a false negative test result on all 4 tests (Figure $2 \mathrm{~A}$ ). The remaining false negatives were primarily found within a single test, indicating that no relationship was present between the tests with respect to false-negative results. Eight cows were false positive on all 4 tests, which was possibly explained by embryonic loss between d 28 (PAG sample) and d 35 to 38 (transrectal ultrasonography; Figure 2B). A false-positive result is a recognized limitation of early pregnancy diagnosis performed within 4 wk after AI because approximately 10 to $20 \%$ of pregnant dairy cows undergo embryonic loss after wk 4 (Giordano et al., 2013). A cow with embryonic loss during this period will initially test pregnant and later be found not pregnant when the reference standard test is applied (Szenci et al., 2003; Giordano et al., 2012; Pohler et al., 2016). As with all early pregnancy tests based on PAG or ultrasound, cows need to be rechecked for pregnancy after the initial period of embryonic loss (Giordano et al., 2013).

The reason for the lesser specificity and PPV of the rapid visual test (Table 1 ) is that 12 cows were diagnosed pregnant based on visual interpretation but were not pregnant based on the OD interpretation of the exact same well (Figure 2B). The average OD for these 12 cows was $0.22 \pm 0.03$ compared with the pregnancy OD cutpoint of 0.304 and average OD of the remaining pregnant cows of $0.51 \pm 0.01(P<0.001)$. The cows correctly classified as not pregnant had an average rapid visual OD of $0.11 \pm 0.01(P<0.001)$. When these 12 
samples were reanalyzed and interpreted visually, the result was negative and the specificity improved to 93 $\pm 2 \%$ for the rapid visual test. Repeating the assay for cows with a faint signal may resolve false positives. With respect to on-farm application, the slightly lower specificity means that cows that are not pregnant are diagnosed as pregnant and this phenomenon reinforces the need for rechecking cows with a positive test result after the period of embryonic loss has subsided. The sensitivity and NPV of the visual test was almost 100\% and not different from other tests. This indicates that very few truly pregnant cows are misdiagnosed as not pregnant.

Cohen's kappa statistics were calculated to assess the agreement between the different tests with respect to the diagnosis of pregnancy (Table 2). Agreement was extremely high for tests based solely on OD. Agreement for the rapid visual test assessed visually and other tests based on OD was slightly less but would be considered almost perfect $(>0.81$; Viera and Garrett, 2005). Insemination number and days open at the time of sampling did not affect the OD for any test. Pregnant primiparous cows had greater OD $(0.54 \pm$ $0.02)$ than pregnant multiparous cows $(0.49 \pm 0.01 ; P$ $<0.05)$ when the rapid visual test was used. There was no effect of parity on OD for the plasma or milk tests.

The circulating concentrations of PAG increase approximately $25 \mathrm{~d}$ after $\mathrm{AI}$ in pregnant cows (Green et al., 2005). The concentrations continue to increase until approximately d 35 and then decrease for a period of 3 to 4 wk before increasing again until the end of pregnancy (Ricci et al., 2015). The underlying cause for the changes in circulating PAG are unclear, but the interpretation of the test result can be affected in primiparous and multiparous cows (Ricci et al., 2015). We examined whether the PAG signal changed during early gestation when the rapid visual test was used. In a separate study using a prototype kit with identical chemical reagents, lactating Holstein cows $(\mathrm{n}=291)$ from 4 commercial confinement dairy farms in central and western Kentucky were enrolled in May and June 2015. Cows were between 25 to $95 \mathrm{~d}$ after AI on the sampling day. For statistical analysis, cows were grouped by week of pregnancy beginning on d 25. Blood was collected and tests were performed using procedures similar to those described for the Missouri study. The result of the rapid visual test was determined visually and the OD was also measured. The average OD for cows classified not pregnant was $0.21 \pm 0.03$ compared with pregnant $\mathrm{OD}$ of $0.37 \pm 0.01(P<0.001)$. The OD was greatest for pregnant cows sampled from d 25 to 32 and then declined to its lowest level on d 46 to 60 after AI (Figure 3; effect of sampling day; $P<0.01$ ). A subsequent increase occurred in PAG OD (Figure 3). The interpretation was that the OD for the rapid visual test demonstrated the same pattern for PAG during the

Table 1. Sensitivity, specificity, positive predictive value (PPV), negative predictive value (NPV), and accuracy $(\% \pm \mathrm{SE})$ for pregnancy-associated glycoprotein (PAG) tests using plasma and milk and a rapid visual test using whole blood with test results interpreted by using either optical density (OD) or visually when transrectal ultrasonography was used as the reference standard for pregnancy diagnosis in lactating Holstein cows $28 \mathrm{~d}$ after timed AI

\begin{tabular}{|c|c|c|c|c|c|}
\hline Assay & $\begin{array}{c}\text { Sensitivity }^{1} \\
\% \\
\text { (no./no.) }\end{array}$ & $\begin{array}{c}\text { Specificity }^{2} \\
\% \\
\text { (no./no.) }\end{array}$ & $\begin{array}{c}\mathrm{PPV}^{3} \\
\% \\
\text { (no./no.) }\end{array}$ & $\begin{array}{c}\mathrm{NPV}^{4} \\
\% \\
\text { (no./no.) }\end{array}$ & $\begin{array}{c}\text { Accuracy }^{5} \\
\% \\
\text { (no./no.) }\end{array}$ \\
\hline$\overline{\text { Plasma OD }^{6}}$ & $\begin{array}{c}97 \pm 1 \\
(155 / 159)\end{array}$ & $\begin{array}{c}94 \pm 2 \\
(152 / 161)\end{array}$ & $\begin{array}{c}95 \pm 2 \\
(155 / 164)\end{array}$ & $\begin{array}{c}97 \pm 1 \\
(152 / 156)\end{array}$ & $\begin{array}{c}96 \pm 1 \\
(307 / 320)\end{array}$ \\
\hline Milk $\mathrm{OD}^{6}$ & $\begin{array}{c}96 \pm 2 \\
(152 / 159)\end{array}$ & $\begin{array}{c}94 \pm 2 \\
(152 / 161)\end{array}$ & $\begin{array}{c}94 \pm 2 \\
(152 / 161)\end{array}$ & $\begin{array}{c}96 \pm 2 \\
(152 / 159)\end{array}$ & $\begin{array}{c}95 \pm 1 \\
(304 / 320)\end{array}$ \\
\hline Rapid visual $\mathrm{OD}^{6}$ & $\begin{array}{c}95 \pm 2 \\
(151 / 159)\end{array}$ & $\begin{array}{c}93 \pm 2 \\
(150 / 161)\end{array}$ & $\begin{array}{c}93 \pm 2 \\
(151 / 162)\end{array}$ & $\begin{array}{c}95 \pm 2 \\
(150 / 158)\end{array}$ & $\begin{array}{c}94 \pm 1 \\
(301 / 320)\end{array}$ \\
\hline Rapid visual $^{7}$ & $\begin{array}{c}98 \pm 1 \\
(156 / 159)\end{array}$ & $\begin{array}{c}85 \pm 3 \\
(137 / 161)\end{array}$ & $\begin{array}{c}87 \pm 3 \\
(156 / 180)\end{array}$ & $\begin{array}{c}98 \pm 1 \\
(137 / 140)\end{array}$ & $\begin{array}{c}92 \pm 2 \\
(293 / 320)\end{array}$ \\
\hline
\end{tabular}

${ }^{1}$ Number of cows with a correct positive test/the number of cows with a positive ultrasonographic test.

${ }^{2}$ Number of cows with a correct negative test/the number of cows with a negative ultrasonographic test.

${ }^{3}$ Number of cows with a correct positive test/number of cows with a correct positive test + the number of cows with an incorrect positive test.

${ }^{4}$ Number of cows with a correct negative test/number of cows with a correct negative test + the number of cows with an incorrect negative test.

${ }^{5}$ Number of correct blood pregnancy tests/total number of blood pregnancy tests.

${ }^{6}$ Optical density measured by a microtiter plate reader for all samples at a wavelength of $650 \mathrm{~nm}$ for rapid visual and $450 \mathrm{~nm}$ for plasma and milk. In this study, the receiver operator characteristic-determined cutoffs for pregnancy were $0.304,0.860$, and 1.716 for the rapid visual, milk, and plasma assays, respectively.

${ }^{7}$ Cows were classified pregnant if the sample was any shade darker visually than both negative controls. Cows were classified not pregnant if the sample was not darker visually than both negative controls. 
A

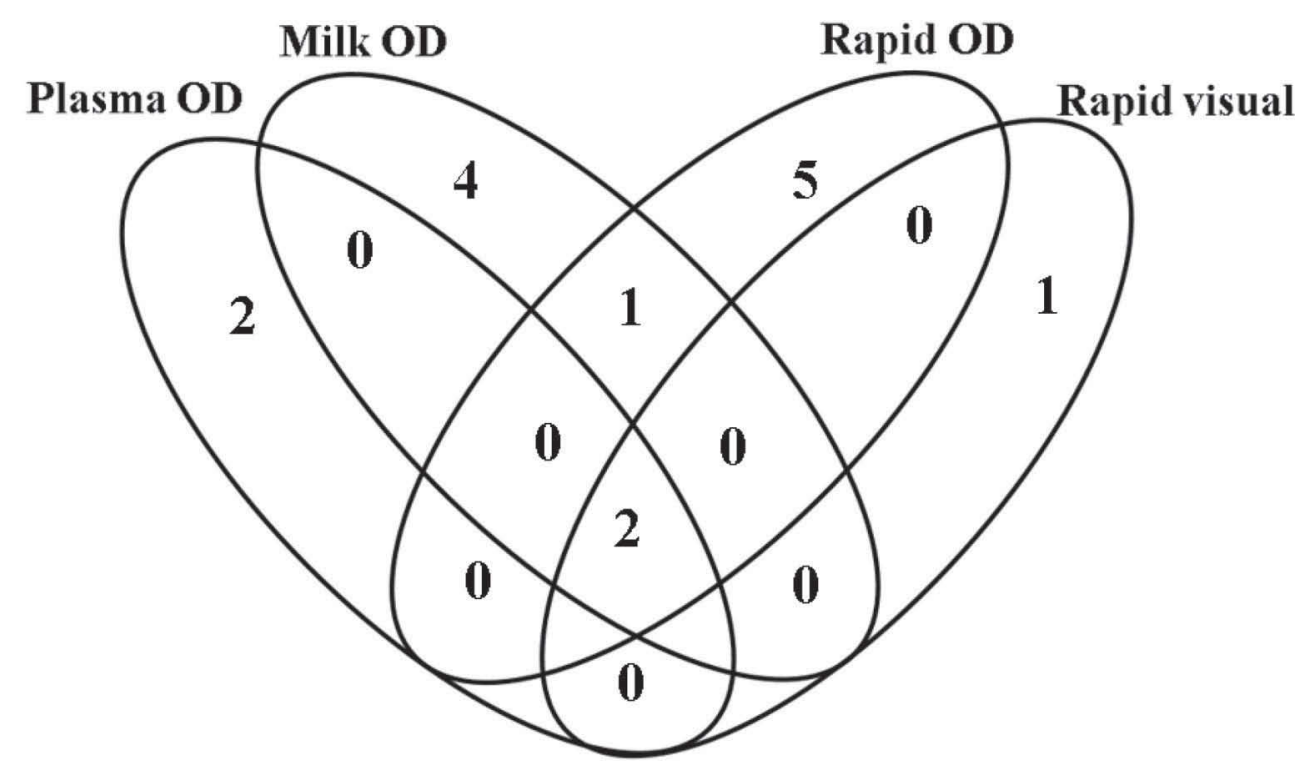

B

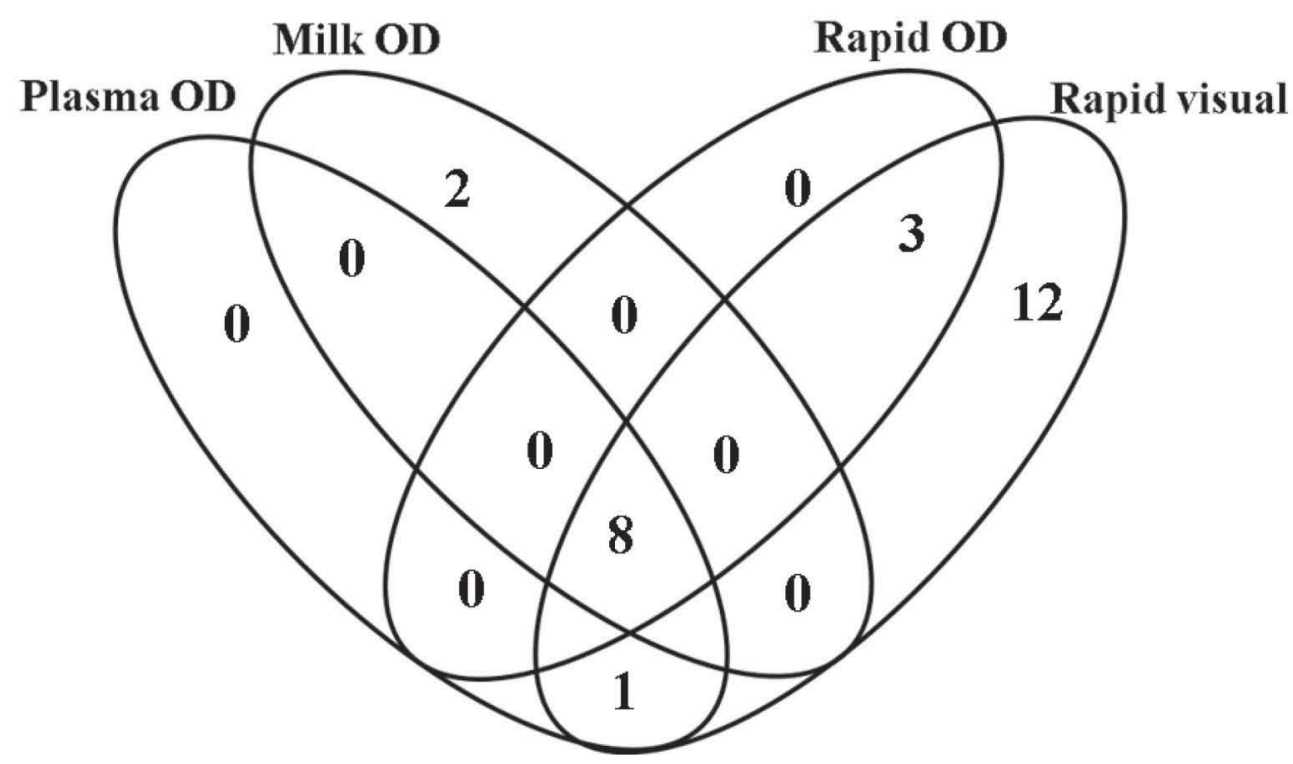

Figure 2. Venn diagrams for bovine chemical pregnancy test in lactating Holstein cows $28 \mathrm{~d}$ after timed AI with transrectal ultrasonography at 35 to $38 \mathrm{~d}$ after timed AI as the reference standard. The number of individual cows shared between the respective tests is shown for cows that were classified as either false negative $(\mathrm{A} ; \mathrm{n}=15$ cows total) or false positive $(\mathrm{B} ; \mathrm{n}=26$ cows total). OD $=$ optical density.

Table 2. Cohen's kappa statistic for bovine chemical pregnancy tests $(\mathrm{n}=320)$ and transrectal ultrasonography measuring inter-test agreement at $28 \mathrm{~d}$ after insemination for pregnancy-associated glycoproteins (PAG) and 35 to $38 \mathrm{~d}$ after AI for transrectal ultrasonography

\begin{tabular}{lccccc}
\hline Item & Ultrasound & $\begin{array}{c}\text { Rapid } \\
\text { visual }\end{array}$ & $\begin{array}{c}\text { Rapid } \\
\text { visual OD }\end{array}$ & Milk OD & Plasma OD \\
\hline Plasma OD & 0.92 & 0.89 & 0.93 & 0.93 & 1 \\
Milk OD & 0.90 & 0.84 & 0.91 & 1 & \\
Rapid visual OD & 0.88 & 0.87 & 1 & & \\
Rapid visual & 0.83 & 1 & & & \\
Ultrasound & 1 & & & & \\
${ }^{1}$ OD = optical density. & & & & &
\end{tabular}




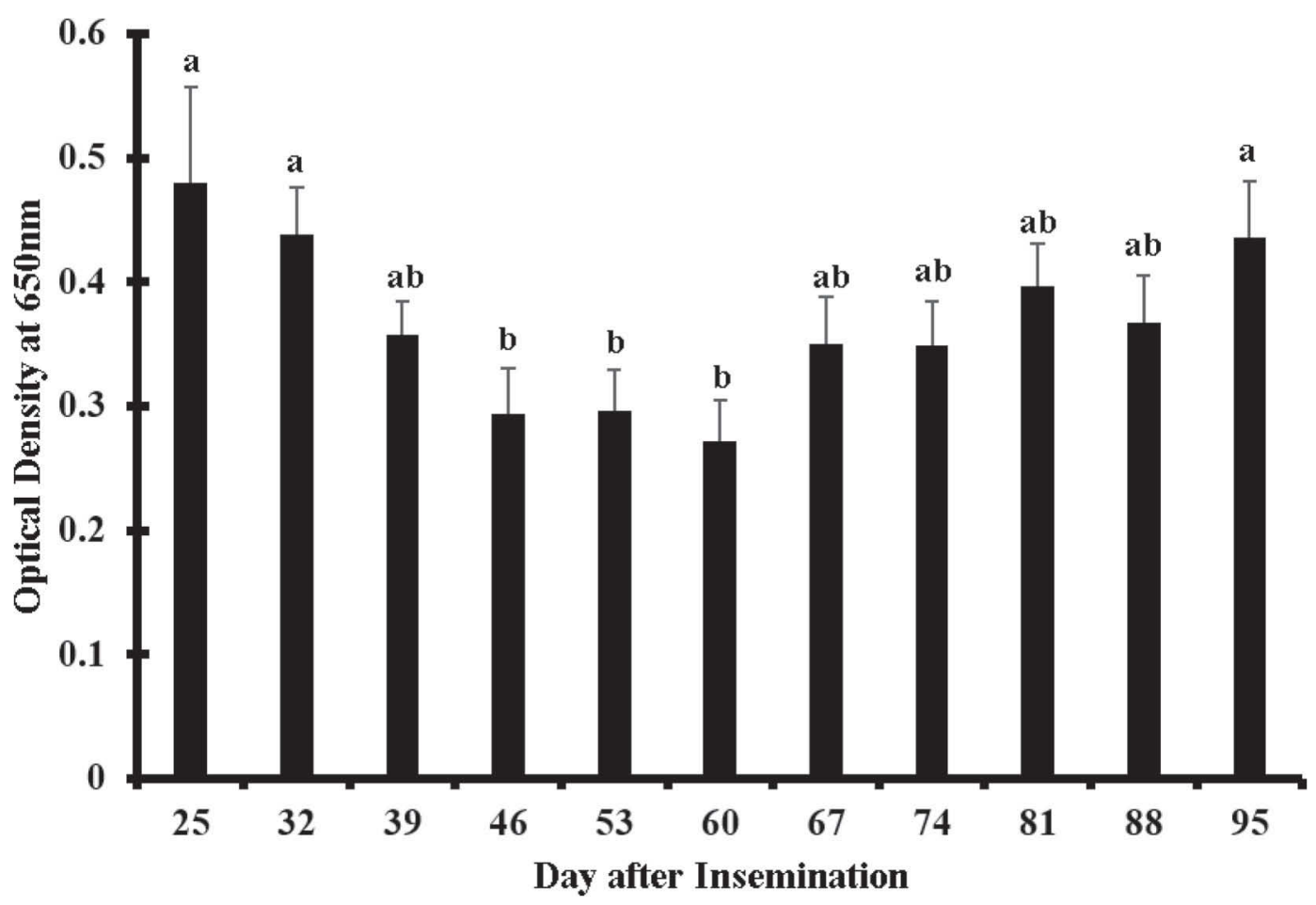

Figure 3. Optical density (OD) at $650 \mathrm{~nm}$ for a rapid visual test from pregnant lactating Holstein cows in central and western Kentucky 25 to $95 \mathrm{~d}$ after insemination. Bars with different letters (a,b) differ at $P<0.05$. Cows were grouped by week with $25 \mathrm{~d}$ including cows that were 25 to $31 \mathrm{~d}$ pregnant; $32 \mathrm{~d}$ including cows that were 32 to $36 \mathrm{~d}$ pregnant, and so on. The average OD for cows classified not pregnant in the same study was $0.21 \pm 0.03$. Error bars $=$ SEM.

first trimester of pregnancy as reported for alternative PAG tests (Ricci et al., 2015).

In conclusion, a rapid visual test had equal sensitivity and accuracy to existing tests. A slightly lower specificity was found when the rapid visual test was read visually. The lower specificity was explained by a small number of cows with a weak signal and falsepositive result. The same wells yielded a negative result (below an established cutpoint) when the OD was measured mechanically with a microtiter plate reader. With respect to on-farm application, the slightly lower specificity reinforces the need for a second pregnancy diagnosis (either chemical test or alternative method) after the period of embryonic loss has subsided. The sensitivity and NPV of the visual test was almost $100 \%$ and not different from other tests. This indicates that very few truly pregnant cows are misdiagnosed as not pregnant when the rapid visual test is used.

\section{ACKNOWLEDGMENTS}

The authors thank Heartland Dairy Farm (La Belle, $\mathrm{MO}$ ) for access to their cows and for the assistance of their employees. The authors also thank Roger MolinaCoto and Holly Ann Thibodeaux from the University of Missouri for their assistance in sample collections in Northeast Missouri. The authors thank Kentucky dairy farmers Billy Riney, Josh Duvall, Mike Hunt, and Bradley Elkins for access to their cows in Kentucky. The authors greatly appreciate Susan Hayes, Hugo Hamilton, Denise Ray, Jeffrey Bewley, Georgia Skelton, Amanda Lee, Karmella Dolecheck, Nicky Tsai, and Tatiana Muñoz from the University of Kentucky for their assistance in sample collection in central and western Kentucky. The trial was funded by the Food for the 21st Century Program of the University of Missouri. The ELISA test kits used in this work were provided by IDEXX (Westbrook, ME). L. M. Mayo was supported by a fellowship from the National Institutes of Health through the Initiative for Maximizing Student Development.

\section{REFERENCES}

Fricke, P. M. 2002. Scanning the future: Ultrasonography as a reproductive management tool for dairy cattle. J. Dairy Sci. 85:19181926.

Giordano, J. O., P. M. Fricke, and V. E. Cabrera. 2013. Economics of resynchronization strategies including chemical tests to identify nonpregnant cows. J. Dairy Sci. 96:949-961.

Giordano, J. O., J. N. Guenther, G. Lopes Jr., and P. M. Fricke. 2012. Changes in serum pregnancy-associated glycoprotein, pregnancy- 
specific protein $\mathrm{B}$, and progesterone concentrations before and after induction of pregnancy loss in lactating dairy cows. J. Dairy Sci. 95:683-697.

Green, J. A., T. E. Parks, M. P. Avalle, B. P. Telugu, A. L. McLain, A. J. Peterson, W. McMillan, N. Mathialagan, R. R. Hook, and S. Xie. 2005. The establishment of an ELISA for the detection of pregnancy-associated glycoproteins (PAGs) in the serum of pregnant cows and heifers. Theriogenology 63:1481-1503.

Green, J. C., D. H. Volkmann, S. E. Poock, M. F. McGrath, M. Ehrhardt, A. E. Moseley, and M. C. Lucy. 2009. Technical note: A rapid enzyme-linked immunosorbent assay blood test for pregnancy in dairy and beef cattle. J. Dairy Sci. 92:3819-3824.

Karen, A., N. M. De Sousa, J. F. Beckers, Á. C. Bajcsy, J. Tibold, I. Mádl, and O. Szenci. 2015. Comparison of a commercial bovine pregnancy-associated glycoprotein ELISA test and a pregnancyassociated glycoprotein radioimmunoassay test for early pregnancy diagnosis in dairy cattle. Anim. Reprod. Sci. 159:31-37.

Lawson, B. C., A. H. Shahzad, K. A. Dolecheck, E. L. Martel, K. A. Velek, D. L. Ray, J. C. Lawrence, and W. J. Silvia. 2014. A pregnancy detection assay using milk samples: Evaluation and considerations. J. Dairy Sci. 97:6316-6325.

LeBlanc, S. J. 2013. Short communication: Field evaluation of a pregnancy confirmation test using milk samples in dairy cows. J. Dairy Sci. 96:2345-2348.

Pohler, K. G., M. H. Pereira, F. R. Lopes, J. C. Lawrence, D. H. Keisler, M. F. Smith, J. L. Vasconcelos, and J. A. Green. 2016. Circulating concentrations of bovine pregnancy-associated glycoproteins and late embryonic mortality in lactating dairy herds. J. Dairy Sci. 99:1584-1594.
Ricci, A., P. D. Carvalho, M. C. Amundson, R. H. Fourdraine, L. Vincenti, and P. M. Fricke. 2015. Factors associated with pregnancyassociated glycoprotein (PAG) levels in plasma and milk of Holstein cows during early pregnancy and their effect on the accuracy of pregnancy diagnosis. J. Dairy Sci. 98:2502-2514.

Silva, E., R. A. Sterry, D. Kolb, N. Mathialagan, M. F. McGrath, J. M. Ballam, and P. M. Fricke. 2007. Accuracy of a pregnancyassociated glycoprotein ELISA to determine pregnancy status of lactating dairy cows twenty-seven days after timed artificial insemination. J. Dairy Sci. 90:4612-4622.

Silva, E., R. A. Sterry, D. Kolb, N. Mathialagan, M. F. McGrath, J. M. Ballam, and P. M. Fricke. 2009. Effect of interval to resynchronization of ovulation on fertility of lactating Holstein cows when using transrectal ultrasonography or a pregnancy-associated glycoprotein enzyme-linked immunosorbent assay to diagnose pregnancy status. J. Dairy Sci. 92:3643-3650.

Snedecor, G. W., and W. G. Cochran. 1989. Statistical Methods. 8th ed. Iowa State University Press, Ames.

Szenci, O., J.-F. Beckers, J. Sulon, M. Bevers, L. Börzsönyi, L. Fodor, F. Kovacs, and M. Taverne. 2003. Effect of induction of late embryonic mortality on plasma profiles of pregnancy associated glycoprotein 1 in heifers. Vet. J. 165:307-313.

Viera, A. J., and J. M. Garrett. 2005. Understanding interobserver agreement: The kappa statistic. Fam. Med. 37:360-363.

Wallace, R. M., K. G. Pohler, M. F. Smith, and J. A. Green. 2015. Placental PAGs: Gene origins, expression patterns, and use as markers of pregnancy. Reproduction 149:R115-R126. 